\title{
Analisis Implementasi Total Quality Management (TQM) Pada Kasus Pending Klaim Jaminan Kesehatan Nasional (JKN) Di RSUD Kendal Tahun 2018
}

\author{
Faik Agiwahyuanto*, Shinta Octaviasuni*, dan Moh.Umar Nauful Fajri** \\ *Dosen Program Studi D-3 Rekam Medis dan Informasi Kesehatan Fakultas Kesehatan \\ Universitas Dian Nuswantoro Semarang, **Mahasiswa Program Studi D-3 Rekam Medis dan \\ Informasi Kesehatan Fakultas Kesehatan Universitas Dian Nuswantoro Semarang \\ Email: faik.agiwahyuanto@dsn.dinus.ac.id
}

\section{ABSTRACT}

Improvements in hospitals are needed to become a going concern hospital. One strategy that can be applied is Total Quality Management (TQM). TQM seeks continuous improvement of all hospital functions. The National Health Insurance Program (JKN) has been run by the Regional Hospital General Hospital (RSUD) Dr. H. Soewondo Kendal as of January $1^{\text {st }}$, 2014. Health financing is the most important part of implementing JKN held in hospitals by BPJS Kesehatan through submission of claims. During JKN implementation in Kendal General Hospital, problems were found between the difference visits of BPJS Health patients to hospitalizations and Health BPJS claimed, thus causing pending cases of late claims. File claims that are late in submission will be included in claim process the following month.

Analyze the pending causes of the Health BPJS file based on TQM implementation.

This type of research uses quantitative phenomenological methods and case study research designs. Research subjects are 38 people. Research instrument are questionnaier and patient claim file by paying BPJS Kesehatan. Data analysis using Importance Performance Analysis (IPA) technique.

Pending causes of JKN claims according to the TQM implementation the main priority factors are man and methods. Maintain factors are material, machine, and money

$T Q M$ can improve the performance of medical records employees who take care of JKN klaim.

Recommendation to RSUD dr. H. Soewondo Kendal management can allocate its resources to improve the $T Q M$ implementation can better meet the JKN claims set.

Keywords : TQM, pending, BPJS claims

\section{PENDAHULUAN}

Setiap Rumah Sakit (RS) tentu mempunyai strategi dan cara tersendiri dalam menghadapi masalah. Salah satu strategi yang dapat diterapkan menurut Kaynak adalah Total Quality Management (TQM). ${ }^{1} \quad$ TQM didefinisikan sebagai sebuah filosofi manajemen holistik yang mengupayakan perbaikan secara terus menerus dalam semua fungsi organisasi dan dapat dicapai jika konsep kualitas total digunakan dari perolehan sumber daya ke layanan pelanggan setelah penjualan. Larina menjelaskan bahwa TQM memungkinkan untuk memprediksi prospek di masa depan, kemudian memecahkan masalah yang mungkin terjadi, dan menemukan cara untuk mencapainya. ${ }^{2}$ TQM menurut Ejionueme adalah sebuah filosofi manajemen dan praktik yang 
bertujuan untuk memanfaatkan sumber daya manusia dan material dari setiap organisasi dengan cara yang paling efektif untuk mencapai tujuan organisasi sehingga dalam penerapan TQM, tujuan akhir sebuah organisasi adalah suatu sistem perbaikan terus menerus untuk mencapai kepuasan pelanggan. $^{3}$

Berdasarkan Undang-Undang Republik Indonesia Nomor 36 Tahun 2009 Tentang Kesehatan, disebutkan bahwa kesehatan merupakan hak asasi manusia dan menjadi salah satu unsur kesejahteraan yang harus diwujudkan sesuai dengan citacita dari bangsa Indonesia. Pemerintah Indonesia sudah menjalankan program Jaminan Kesehatan Nasional (JKN) pada awal tahun 2014 yang mengacu pada Peraturan Menteri Kesehatan (PMK) No. 28 Tahun 2014 tentang pedoman pelaksanaan JKN. Pelaksanaan program JKN di rumah sakit membuat rumah sakit hanya melakukan pelayanan kesehatan perorangan yang bersifat spesialistik atau sub spesialistik (PMK No. 59 Tahun 2014). Selain itu, pengelolaan rumah sakit tidak semudah pengelolaan sebuah klinik. ${ }^{4} \mathrm{Hal}$ ini menunjukan bahwa diperlukan pengelolaan khusus untuk pelaksanaan program JKN di rumah sakit.

Badan Penyelenggaraan Jaminan Sosial (BPJS) Kesehatan sebagai badan yang menyelenggarakan JKN dibentuk oleh pemerintah untuk menanggulangi kebutuhan kesehatan masyarakat Indonesia yang berdasarkan Peraturan Presiden Nomor 12 tahun 2013 dan mulai aktif beroperasi pada tanggal 1 Januari tahun 2014. Landasan hukum lain penyelenggaraan BPJS Kesehatan dari UUD 1945, kemudian Undang-Undang Nomor 40 Tahun 2004 tentang Sistem Jaminan Sosial Nasional serta UndangUndang Nomor 24 Tahun 2011 tentang Badan Penyelenggara Jaminan Sosial Kesehatan. BPJS Kesehatan dibentuk sebagai lembaga layanan jasa perlu mengutamakan pelayanan yang baik dan kepuasan pelanggan yaitu peserta BPJS Kesehatan. Pembiayaan kesehatan merupakan bagian terpenting implementasi JKN yang diselenggarakan di rumah sakit oleh BPJS melalui pengajuan klaim. Dengan sistem pengembangan mutu yang diterapkan BPJS Kesehatan sesuai dengan ISO 9001 menandakan bahwa BPJS Kesehatan sudah menerapkan strategi TQM. Sistem pengembangan mutu yang sesuai dengan ISO 9001 dapat menjadi acuan BPJS Kesehatan dalam memberikan pelayanan yang maksimal terhadap pelanggan. $^{5}$

Hutomo dan Ratih mengemukakan bahwa TQM sebagai salah satu sistem dianggap mampu secara ampuh untuk mempengaruhi kepuasan pelanggan. ${ }^{6}$ Chiguvi menjelaskan TQM yang diterapkan pada perusahaan mempunyai fokus perusahaan yang paling utamanya adalah ke pelanggan dan tujuan utamanya untuk pemenuhan kebutuhan pelanggan. ${ }^{7}$ Oleh karena itu, terkait dengan permasalahan yang ada, peneliti berpendapat bahwa diperlukan adanya penerapan TQM yang baik untuk mengurangi hal-hal yang terjadi. Hal tersebut sesuai dengan Gul yang menjelaskan bahwa penggunaan pendekatan TQM dapat menjadi alat yang andal dalam melatih tenaga kerja yang andal dan berdedikasi. ${ }^{8}$

Terdapat beberapa penelitian tentang permasalahan penerapan BPJS Kesehatan. Berdasarkan penelitian Putra menunjukan bahwa dalam pelaksanaan JKN ditemukan berbagai kendala salah satunya terkait pembiayaan seperti keterlambatan pencairan klaim akibat keterlambatan proses pemberkasan klaim dan adanya perbedaan nilai tarif pelayanan terhadap paket pelayanan INA-CBGs. ${ }^{9}$ Penelitian Tettey, dkk menemukan klaim yang ditolak menyebabkan pembayaran fasilitas kesehatan tidak sesuai dengan biaya yang diajukan. Akibat adanya klaim 
yang ditolak, fasilitas kesehatan di Kassena Nankana kehilangan biaya $10,65 \%$ dari biaya klaim yang diajukan dan fasilitas kesehatan yang ada di distrik Builsa kehilangan biaya $14,48 \%$ dari klaim yang diajukan. ${ }^{10}$ Hal ini menunjukan bahwa terjadinya klaim ditolak dapat menyebabkan kerugian bagi rumah sakit, khususnya rumah sakit milik pemerintah yang banyak menerima pasien jaminan kesehatan sehingga mengalami kerugian akibat ketidaksesuaian pembiayaan pelayanan dengan jumlah klaim yang dibayarkan. ${ }^{11}$

$$
\text { Pemaparan PERSI }
$$

menyebutkan bahwa aliran kas beberapa rumah sakit terganggu akibat adanya permasalahan dalam pembayaran klaim. ${ }^{12}$ Penelitian Shobirin menyebutkan bahwa keterlambatan pembayaran klaim Askeskin berpengaruh pada cash flow rumah sakit sehingga RSUD Gunung Jati harus menunda pembayaran kewajiban pada pegawai dan pemasok serta memangkas biaya pemeliharaan. ${ }^{13}$ Hal itu juga berdampak pada kinerja pegawai dan ketersediaan supplies yang dapat berpengaruh pada pelayanan pasien peserta Askeskin di RSUD gunung Jati. Kasus klaim ditolak maka rumah sakit akan kehilangan biaya yang sudah dikeluarkan dan dapat mengalami kerugian.

Salah satu faktor penting yang menentukan suatu klaim ditolak atau diterima adalah akurasi pengkodean diagnosis dan tindakan pada dokumen rekam medis. Apabila terdapat kesalahan dalam melakukan pengkodean maka akan mempengaruhi kode DRG (Diagnosis Related Groups) kasus dan akan mempengaruhi biaya pengajuan klaim. ${ }^{11}$ Hal ini juga sesuai dengan penelitian yang dilakukan oleh Tettey, dkk didapatkan penyebab klaim ditolak adalah salah mengutip diagnosis. Penyebab lain yaitu karena tidak ada bukti pelayanan yang diajukan dan klien yang tidak eligibel akibat kartu asuransi kesehatan nasional kadaluarsa atau nomor asuransi yang tidak dikenali oleh provider serta obat yang digunakan tidak sesuai dengan yang ada didaftar obat dan biaya obat yang dilebihkan. ${ }^{10}$

Penelitian Ulfah, Kresnowati, dan Ernawati tentang hubungan kelengkapan dokumen rekam medis dengan persetujuan klaim Jamkesmas oleh verifikator dengan sistem INA-DRG di RSI Sultan Agung Semarang juga menunjukan hasil yang sama. ${ }^{14}$ Berkas klaim yang tidak disetujui oleh verifikator disebabkan karena belum disertai dengan diagnosis dokter, hasil pemerikasaan penunjang diagnosis, dan permasalahan pada aturan pengkodean. Sistem INA-CBGs memang telah diterapkan di FKRTL sejak pelaksanaan Jamkesmas tahun 2010 (PMK No. 27 tahun 2014). Berdasarkan penelitian Kusairi bahwa berkas klaim yang tidak lengkap dapat disebabkan oleh proses administrasi, pemahaman dan kinerja pertugas terhadap kelengkapan berkas klaim yang masih kurang, tidak adanya Standar Operasional Prosedur (SOP) serta evaluasi pelaksanaan program jaminan yang belum dilaksanakan. ${ }^{15}$

Klaim yang bermasalah juga ditemukan dalam penelitian Mahesa bahwa sebagian besar klaim yang bermasalah dikarenakan ketidaklengkapan administrasi klaim, pengecualian dan batas biaya. ${ }^{16}$ Penelitian Cahyaningtyas bahwa penagihan klaim belum lancar dikarenakan masih ada klaim yang tidak dibayar dan terlambat untuk diajukan. ${ }^{17}$ Pada penelitian tersebut kelancaran klaim dilihat menggunakan pendekatan sistem. Digambarkan pada elemen input bahwa kebijakan terkait pelayanan JPK Gakin dan SKTM di rumah sakit tersebut belum tersosialisasi dengan baik, sumber daya manusia yang sangat kurang, sarana dan prasarana yang digunakan dalam pelayanan administrasi JPK Gakin dan SKTM tidak memadai 
(billing masih manual). ${ }^{17}$ Aspek proses ditemukan bahwa bukti tindakan pasien tidak lengkap akibat kelalaian dokter dan perawat serta tahap verifikasi dan rekapitulasi yang sering mengalami kesalahan akibat dilakukan bersamaan dengan pelayanan administrasi pasien. Hal ini juga didukung oleh penelitian Tettey, dkk bahwa ditemukan beberapa kendala dalam proses pengajuan klaim asuransi kesehatan Gana beberapa diantaranya yaitu formulir klaim belum diisi dengan lengkap dan kurangnya petugas yang memiliki kompetensi. ${ }^{10}$

Rumah Sakit Umum Daerah (RSUD) dr. H. Soewondo dipilih sebagai tempat penelitian karena merupakan rumah sakit milik pemerintah Kabupaten Kendal tipe B dan menjadi rumah sakit rujukan pertama di Kabupaten Kendal. Selain itu, rumah sakit ini masih tergolong rumah sakit yang sudah lama berdiri dan dioperasikan pada tahun 1988 serta sudah menjalankan program JKN per 1 Januari 2014. Terlebih berdasarkan data jumlah kunjungan pasien tahun 2015 diketahui bahwa pasien yang berkunjung ke RSUD dr. H. Soewondo Kendal didominasi oleh pasien pengguna JKN. Berdasarkan hasil wawancara dan observasi di RSUD dr. H. Soewondo Kendal ditemukan bahwa dalam pelaksanaan JKN di RSUD dr. $\mathrm{H}$. Soewondo Kendal terutama pada pelayanan administrasi, ditemukan masalah seperti gangguan pada penggunaan aplikasi pembuat Surat Eligibilitas Peserta (SEP), Aplikasi Indonesia Case Based Groups (INA-CBGs), dan Sistem Informasi Manajeman Rumah Sakit (SIMRS) pendaftaran yang diakibatkan oleh ketidakstabilan jaringan, belum adanya SOP SIMRS yang menyeluruh sehingga memungkinkan berkas klaim pasien JKN menjadi tidak lengkap karena tercecer dan memungkinkan terjadi keterlambatan dalam proses kode dan entri data, dan ditemukan adanya klaim pasien JKN yang ditunda (pending) oleh verifikator klaim JKN.

Data klaim di RSUD dr. $\mathrm{H}$. Soewondo Kendal menunjukan bahwa dalam pengajuan klaim pada tahun 2016 dan 2017 terdapat kasus klaim ditolak baik untuk rawat jalan dan rawat inap. Pada tahun 2016 kasus klaim JKN yang ditunda pada pelayanan rawat inap sebanyak 100 dari 500 klaim yang diajukan. Pada tahun 2017 kasus klaim yang ditolak pada pelayanan rawat inap sebanyak 105 kasus 500 klaim yang diajukan. Data tersebut menggambarkan bahwa terjadi peningkatan kasus klaim JKN yang ditunda pada pelayanan rawat inap dari tahun 2016 sampai 2017 seiring dengan bertambahnya jumlah klaim yang diajukan dan jumlah kunjungannya. Oleh karena itu, penelitian ini akan difokuskan pada permasalahan klaim JKN yang ditunda pada layanan rawat inap di RSUD dr. H. Soewondo Kendal.

Peneliti tertarik untuk meneliti dan menganalisis klaim yang ditunda berdasarkan kondisi berkas klaim menggunakan pendekatan TQM di RSUD dr. H. Soewondo Kendal. Pengukuran penerapan TQM diukur dengan kuesioner dan dianalisis dengan pendekatan Importance Performance Analysis (IPA). Pentingnya penerapan TQM di Rumah Sakit akan berdampak pada peningkatan kualitas pelayanan, maka penulis mengajukan penelitian yang berjudul "Analisis Implementasi Total Quality Management (TQM) Pada Kasus Pending Klaim Jaminan Kesehatan Nasional (JKN) Di RSUD Kendal”.

\section{METODE PENELITIAN}

Jenis penelitian menggunakan metode kuantitatif fenomenologi dan rancangan penelitian studi kasus. Sampel penelitian adalah petugas rekam medis RSUD dr. $\mathrm{H}$. Soewondo Kendal sebanyak 38 orang. Instrumen penelitian yaitu kuesioner 
dengan skala jawaban berada pada rentang 1-5 mulai dari Sangat Baik sampai Sangat Tidak Baik dan berkas klaim pasien dengan cara bayar BPJS sebanyak 30 berkas. Analisis data menggunakan teknik Importance Performance Analysis (IPA) atau analisis tingkat kepentingan dan kinerja kualitas pelayanan. Dalam penelitian ini digunakan satu variabel penelitian yaitu implementasi TQM yang ditinjau dari komponen man, metode, material, machine, dan money.

$\mathrm{T}_{\mathrm{ki}}=\frac{\mathrm{X}_{\mathrm{i}}}{\mathrm{Y}_{\mathrm{i}}} \times 100 \%$

Perhitungan TQM:

Keterangan:

Tki $=$ Tingkat kesesuaian

$\mathrm{Xi}=$ Skor penilaian kinerja (performance)

$\mathrm{Yi}=$ Skor kepentingan Implementasi TQM:

$\mathrm{X}=\frac{\sum \mathrm{X}_{\mathrm{i}}}{\mathrm{n}}$

$\mathrm{Y}=\frac{\sum \mathrm{Y}_{\mathrm{i}}}{\mathrm{n}}$

Keterangan:

$\mathrm{X}=$ Skor rata-rata tingkat kinerja implementasi TQM

$\mathrm{Y}=$ Skor rata-rata tingkat harapan implementasi TQM

$\mathrm{n}=$ Sampel

Kategori TQM:

0-20 $=$ Sangat Tidak Memuaskan

$>20-40=$ Tidak Memuaskan

$>40-60=$ Cukup Memuaskan

$>60-80=$ Memuaskan

$>80-100=$ Sangat Memuaskan

Perhitungan IPA sebagai berikut:

Kelas tertinggi $=5$

Kelas terendah $=1$

Lebar interval $=\frac{\text { Jarak Pengukuran }}{\text { Jumlah Interval }}$

$$
\begin{aligned}
& =\frac{\text { Nilai Tertinggi }- \text { Nilai Terendal }}{\text { Jumlah Interval }} \\
& =\frac{5-1}{5} \\
& =0,8
\end{aligned}
$$

Kategori IPA:

Nilai $>1,0-1,8=$ Sangat Tidak Penting/Baik
Nilai $>1,8-2,7=$ Tidak Penting/Baik

Nilai $>2,7-3,6=$ Cukup Penting/Baik

Nilai $>3,6-4,5=$ Penting/Baik

Nilai $>4,5-5=$ Sangat Penting/Baik

Setelah dilakukan penghitungan dari masing-masing atribut yang dilakukan dengan rumus di atas, selanjutnya akan diukur tingkat implementasi TQM sebagai berikut:

\section{Kepentingan}

\begin{tabular}{l|lr}
$\begin{array}{l}\text { A. Konsentrasi di sini } \\
\text { (prioritas utama) }\end{array}$ & $\begin{array}{l}\text { B. Pertahankan } \\
\text { prestasi }\end{array}$ \\
\hline C. Prioritas Rendah & $\begin{array}{l}\text { D. Mungkin terlalu } \\
\text { berlebihan }\end{array}$ & X \\
\hline
\end{tabular}

\section{Pelaksanaan}

Gambar 1. Diagram Kartesius

\section{HASIL DAN PEMBAHASAN}

Dari 30 berkas klaim yang diambil terdapat 12 kasus yang terdapat kesalahan. Kesalahan tersebut ada pada relaksasi kode diagnosis utama. Dalam penanganannya sudah sesuai teori dengan menggunakan RULE MB 1-MB 5. Berkas klaim dikembalikan ke rumah sakit karena adanya permasalahan terkait dengan diagnosis utama atau yang ditegakkan belum sesuai dengan prosedur yang dilakukan. Faktor penyebab pending klaim dari BPJS RSUD dr. H. Soewondo Kendal menurut TQM antara lain:

Tabel 1. Ringkasan Tingkat Kepuasan Karyawan Atas Atribut Penelitian

\begin{tabular}{clcc}
\hline No & \multicolumn{1}{c}{ Atribut } & Tki (\%) & Kategori \\
\hline 1 & Faktor Men $(\mathrm{X} 1)$ & 70,9 & Memuaskan \\
2 & $\begin{array}{l}\text { Faktor Metode } \\
\text { (X2) }\end{array}$ & 67,7 & Memuaskan \\
3 & $\begin{array}{l}\text { Faktor Material } \\
\text { (X3) }\end{array}$ & 70,2 & Memuaskan \\
4 & $\begin{array}{l}\text { Faktor Machine } \\
\text { (X4) }\end{array}$ & 69,8 & Memuaskan \\
5 & $\begin{array}{l}\text { Faktor Money } \\
\text { (X5) }\end{array}$ & 64,5 & Memuaskan \\
\hline & Sumber: Data Primer Diolah (2018) & \\
& &
\end{tabular}

Berdasarkan tabel 1 bahwa ringkasan tingkat kepuasan karyawan atas atribut penelitian bahwa semua kategori termasuk memuaskan. 
Tabel 2. Perhitungan Rata-Rata Penilaian Harapan dan Kinerja Atribut Penelitian

\begin{tabular}{clcccc}
\hline No & \multicolumn{1}{c}{ Atribut } & Rerata Harapan (Y) & Kategori & Rerata Kinerja (X) & Kategori \\
\hline 1 & Faktor Men (X1) & 3,9 & Baik & 2,8 & Baik \\
2 & Faktor Metode (X2) & 4,4 & Baik & 2,9 & Baik \\
3 & Faktor Material (X3) & 4,3 & Baik & 3,0 & Baik \\
4 & Faktor Machine (X4) & 4,4 & Baik & 2,9 & Baik \\
5 & Faktor Money (X5) & 4,5 & Baik & 2,9 & Baik \\
\hline & Rata-rata & $\mathbf{4 , 3}$ & & $\mathbf{2 , 9}$ & \\
\hline
\end{tabular}

Sumber: Data Primer Diolah (2018)

Berdasarkan tabel 2, hasil semua perhitungan rata-rata penilaian harapan dan kinerja atribut penelitian kategori baik baik.

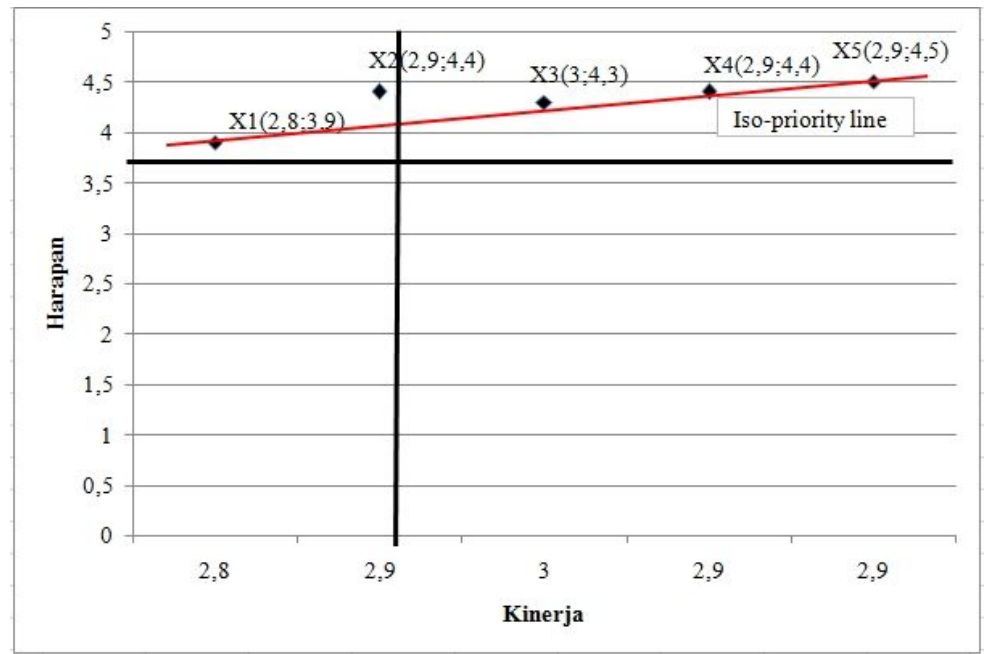

Sumber: Data Primer Diolah (2018)

Gambar 2. Diagram Kartesius Variabel Implementasi TQM

Berdasarkan diagram kartesius di atas terlihat bahwa dari 5 atribut yang digunakan untuk mengukur implementasi TQM dapat dijelaskan sebagai berikut:

Kuadran A (Konsentrasi di Sini/Prioritas Utama) adalah X1 yaitu faktor man dan X2 yaitu faktor metode. Man adalah petugas yang melakukan kegiatan pengelolaan di bagian INA CBGs/casemix di RSUD dr. H. Soewondo Kendal. Menurut Hasibuan, faktor man merujuk pada sumber daya manusia yang dimiliki oleh organisasi. ${ }^{18}$ Faktor man yang menyebabkan keterlambatan dalam pelaksanaan klaim BPJS ditemui pada tenaga bagian casemix berlatar belakang pendidikan bukan rekam medis dan kekurangan tenaga koding. Upaya yang dilakukan petugas dalam mengatasi penyebab keterlambatan dari faktor man adalah memberikan informasi kepada pasien agar kedepannya pasien membawa persyaratan dengan lengkap. Petugas pengodean berkomunikasi dengan dokter agar dokter segera melengkapi resume pasien. Petugas rekam medis juga mengupayakan diadakan perekrutan tenaga rekam medis. ${ }^{19}$

Faktor metode bahwa bagian casemix belum ada Standar Operasional Prosedur (SOP) pengklaiman BPJS. Petugas membentuk tim BPJS merupakan upaya yang dilakukan petugas dalam mengatasi penyebab keterlambatan pada faktor metode yang terdiri dari penanggung jawab BPJS, koder, dan pihak manajemen untuk melakukan sosialisasi dan evaluasi terkait peraturan dari pihak BPJS. Hal ini 
sesuai dengan Peraturan Menteri Kesehatan Nomor 27 tahun 2014 tentang Petunjuk Teknis Sistem INA-CBGs yaitu membentuk tim case mix / tim INA-CBGs rumah sakit akan menjadi penggerak membantu melakukan sosialisasi, monitoring, dan evaluasi implementasi INA-CBGs di rumah sakit.

Kuadran B (Pertahankan) adalah $\mathrm{X} 3$ yaitu faktor material, $\mathrm{X} 4$ yaitu faktor machine, dan X5 yaitu faktor money. Faktor material masih terdapat berkas klaim belum dapat diajukan akibat nomor SEP tidak sesuai atau sering gagal purifikasi. Faktor machine bahwa bagian casemix (INA CBGs) sudah menggunakan komputer dan printer. Machines yang digunakan petugas terkendala pada server dari BPJS yang sering down sehingga petugas tidak dapat mengecek keanggotaan pasien dan bridging system terbatas pada aplikasi SEP saja. Dalam mengatai penyebab keterlambatan dalam faktor machine adalah petugas melakukan backup data secara rutin dan berkomunikasi dengan pihak BPJS. Hal ini sesuai dengan peraturan mentri kesehatan nomor 27 tahun 2013 tentang petunjuk teknis sistem INACBGs. Faktor money yaitu pendapatan rumah sakit tertunda akibat dari berkas klaim yang terlambat (pending) dan berkas klaim yang gagal purifikasi.

Tidak terdapat atribut di kuadran $\mathrm{C}$ (Prioritas Rendah) dan D (Berlebihan).

Tabel 3. Gap dan Penentuan Komponen Prioritas

\begin{tabular}{clcccl}
\hline No & Komponen Implementasi TQM & Harapan & Kinerja & Gap & Keterangan \\
\hline 1 & Faktor Men (X1) & 3,9 & 2,8 & $-1,1$ & Prioritas Utama \\
2 & Faktor Metode (X2) & 4,4 & 2,9 & $-1,5$ & Pertahankan \\
3 & Faktor Material (X3) & 4,3 & 3,0 & $-1,3$ & Pertahankan \\
4 & Faktor Machine (X4) & 4,4 & 2,9 & $-1,5$ & Pertahankan \\
5 & Faktor Money (X5) & 4,5 & 2,9 & $-1,6$ & Pertahankan \\
\hline
\end{tabular}

Sumber: Data Primer Diolah (2018)

Berdasarkan dari diagram kartesius, perhitungan gap, dan garis isoprioritas maka dapat ditetapkan urutan komponen prioritas strategi dalam implementasi TQM yaitu faktor men (X1), faktor metode (X2), faktor material (X3), faktor machine (X4), dan faktor money (X5). TQM berpengaruh lebih kuat terhadap kualitas pelayanan dengan patient safety. $^{20}$ Operational performance rumah sakit milik Pakistan meningkat sebanyak $84 \%$ melalui penerapan TQM. $^{21}$ Penelitian yang dilakukan pada dua rumah sakit besar di Jordania menunjukkan bahwa TQM berkontribusi sebesar $72 \%$ dalam meningkatkan hospital performance. ${ }^{22}$ Implementasi TQM diperlukan dalam pelayanan penanganan pasien sehingga melalui TQM diharapkan akan dapat meminimalkan tingkat keluhan pasien terhadap pelayanan RS. $^{23}$ TQM secara statistik juga terbukti dapat meningkatkan kualitas kinerja dan kinerja keuangan. ${ }^{24-25}$

\section{KESIMPULAN}

Hasil analisis Total Quality Management (TQM) menurut analisis Importance Performance Analysis (IPA) yang dilakukan pada komponen-komponen TQM menunjukkan bahwa terdapat beberapa komponen yang perlu diperbaiki dan ditingkatkan pelaksanaanya, agar tidak terjadi pending klaim JKN di RSUD dr. H Soewondo Kendal. Ada dua komponen yang berada pada kategori prioritas utama yaitu komponen faktor men (X1) dan 
faktor metode (X2) yang perlu dievaluasi dan ditingkatkan kinerja pelaksanaannya. Pada kategori pertahankan ada komponen faktor material (X3), faktor machine (X4), dan faktor money (X5) yang perlu dievaluasi dan terus dimonitor lagi pelaksanaannya. Disarankan bagi manajemen RSUD dr. H. Soewondo Kendal dapat mengalokasikan sumber daya yang dimiliki untuk meningkatkan implementasi TQM agar lebih memenuhi target klaim JKN yang telah ditetapkan.

\section{UCAPAN TERIMA KASIH}

Ucapan terima kasih ditujukan kepada Program Studi D-3 Rekam Medis dan Informasi Kesehatan Universitas Dian Nuswantoro.

\section{DAFTAR PUSTAKA}

1. Kaynak, H. 2003. The relationship between total quality management practices and their effects on firm performance. Journal of Operations Management. Vol. 21: 405-435.

2. Larina, LN. 2015. Practical Application of Total Quality Management System to Education of International Students. ProcediaSocial and Behavior Science. Vol. 215: 9-13.

3. Ejionueme, LK, et al. 2015. Application of Total Quality Management (TQM) in Secondary School Administration in Umuahia Education Zone. Journal of Education and Practice. Vol. 6 (27): 102-111.

4. Satrianegara, MF. 2014. Organisasi dan Manajemen Pelayanan Kesehatan: Teori dan Aplikasi dalam Pelayanan Puskesmas dan Rumah Sakit. Jakarta: Salemba Medika.

5. Mutia, H. 2016. Gambaran Klaim Peserta Jaminan Kesehatan Nasional
Yang Ditolak Pada Layanan Rawat Jalan Di Rumah Sakit Singaparna Medika Citrautama Kabupaten Tasikmalaya Jawa Barat. Skripsi. Universitas Islam Negeri (UIN) Syarif Hidayatullah Jakarta.

6. Hutomo, HT dan Ratih H. 2015. Analisis Implementasi Total Quality Management (TQM) dan Pengaruhnya Terhadap Kepuasan Konsumen dan Services Quality. Jurnal Manajemen Pemasaran. Vol. 4 (2): 136-149.

7. Chiguvi, D. 2016. Impact of Total Quality Management on Customer Satisfaction in the Retail Sector: Case of indigenous Supermarkets in Botswana. European Journal of Business and Management. Vol. 8 (28): 119-131.

8. Gul, A., et al. 2012. Improving Employees Performance Through Total Quality Management.International Journal of Economics and Management Sciences. Vol. 1(8): 1924.

9. Putra, WM. 2014. Analisis Implementasi Kebijakan Jamina Kesehatan Nasional di Rumah Sakit Umum Kota Tangerang Selatan Tahun 2014. Skripsi Universitas Islam Negeri Syarif Hidayatullah. Jakarta.

10. Tettey, SS, et al. 2012. Challenges In Provider Payment Under The Ghana National Health Insurance Scheme: A Case Study Of Claims Management In Two Districts. Ghana Medical Journal, Volume 46, Number 4.

11. Ernawati, D dan Kresnowati L. 2013. Reimbursement Berbasis System Casemix di Beberapa Rumah Sakit yang Melayani Jamkesmas di Kota Semarang. Indonesia Health Informatics Forum Universitas Dian 
Nuswantoro Semarang June 18-20 2013.

12. PERSI. 2016. Refleksi 2 tahun JKN (Jaminan Kesehatan Nasional. (Online). Tersedia:http://www.pdpersi.co.id/kegi atan/bahan_diskusi/refleksi_2thn_j kn.pdf . Diakses pada 27 April 2019.

13. Shobirin, A. 2007. Dampak Keterlambatan Pembayaran Klaim Askeskin Terhdap Cash Flow Dan Pelayanan Pasien Askeskin di RSUD Gunung Jati Kota Cirebon Tahun 2007. Disertasi Fakultas Kesehatan Masyarakat Universitas Indonesia. Depok.

14. Ulfah SM, Kresnowati L, dan Ernawati

D. 2011. Hubungan Kelengkapan Dokumen Rekam Medis Dengan Persetujuan Klaim Jamkesmas Oleh Verifikator Dengan Sistem INA-CBGs Periode Triwulan IV Tahun 2011 Di RSI Sultan Agung Semarang. Penelitian Fakultas Kesehatan Masyarakat Universitas Dian Nuswantoro Semarang.

15. Kusairi, M. 2013. Faktor-Faktor Yang Mempengaruhi Kelengkapan Berkas Klaim Pasien Jamkesmas di RSUD Brigjend. H. Hasan Basry Kandangan. Tesis. Fakultas Kedokteran Universitas Gadjah Mada. Yogyakarta.

16. Mahesa, Y. 2009. Gambaran Klaim Bermasalah Gakin SKTM DKI Jakarta Pada Pelayanan Rawat Inap Di RSUD Pasar Rebo Jakarta Tahun 2008. Skripsi. Fakultas Kesehatan Masayarakat Universitas Indonesia. Depok.

17. Cahyaningtyas, KW. 2012. Gambaran Kelancaran Penagihan Klaim JPK Gakin dan SKTM pada pelayanan Administrasi Pasien Jamina di Rumah Sakit Bhayangkara Tk. I R. Said Sukanto Tahun 2012. Skripsi. Fakultas
Kesehatan Masyarakat Universitas Indonesia. Depok.

18. Hasibuan, M. 2008. Manajemen Sumber Daya Manusia. Jakarta: Bumi Aksara.

19. Noviatri LW dan Sugeng. 2016. Analisis Faktor Penyebab

Keterlambatan Penyerahan Klaim BPJS di RS Panti Nugroho. Jkesvo (Jurnal Kesehatan Vokasional) Vol. 1 No 1-Oktober 2016. ISSN 2541-0644 (Print).

20. Tsai, Y., Wu, Shih-Wang (2011), Enhancing Total Quality Management and Service Quality through Patient Safety Management, Diakses 10 April 2018

www.nedsi.org/proc/2013/proc/p12102 9001.pdf

21. Irfan, S.M., Ijaz, A., Kee, D.M.H and Awan, M (2012), Improving Operational Performance of Public Hospital in Pakistan: a TQM Based Approach, World Applied Sciences Journal, 19 (6): 904-913, 2012 ISSN 1818 -

4952.

DOI:

10.5829/idosi.wasj.2012.19.06.1742.

22. Ali, K.A.M., M.N Alolayyan, F Idris (2012), The Impact of Total Quality Management (TQM) on Hospital Performance in the Jordanian Hospitals: an Empirical Evidence, Global Conference on Operations and Supply Chain Management Proceeding, 12-13 March 2012. Golden Flower Hotel, Bandung, Indonesia .ISBN no: 978-967-570506-9. website: www.globalresearch.com. my

23. Mulyadi, Dedi., Uus M. Fadli, Fitriyani Cipta Kusuma Ningsih (2013), Analisis Manajemen Mutu Pelayanan Kesehatan pada Rumah Sakit Islam Karawang, Jurnal Manajemen, 10 (3), 1203-1219. 
24. Muttaqin, Galih Fajar dan Rita Dharmayanti (2015), Pengaruh Implementasi Total Quality Management terhadap Kinerja Keuangan dengan Kualitas Kinerja Keuangan dengan Kualitas Kinerja sebagai Variabel Intervening, Jurnal Akuntansi, 19 (1), 68-78.

25. Fitriarini, Riyanti Aprilia (2015), Pengaruh Penerapan Total Quality Management (TQM) terhadap Kinerja Keuangan pada Rumah Sakit di Surabaya, STIE Perbanas Surabaya. 